\title{
The changing characteristic analysis of the landslide stability under the
}

\section{water dropping condition}

\author{
Fei Sun ${ }^{1, a^{*}}$, Chongyang Qiu ${ }^{1, b}$ Xue liang $\mathrm{Li}^{1, \mathrm{c}}$ \\ ${ }^{1}$ China Three Gorges University, China \\ a1746303811@qq.com, b1048036522@qq.coml, 417886179@qq.com
}

Key words: Reservoir landslide; Permeability coefficient; Stability coefficient

Abstract: The reservoir landslide stability is closely related to the fluctuation of reservoir level. The main influence factors are fluctuation rate and permeability of landslides. The landslide was chosen as the research object in the three gorges reservoir area, and studied the changing characteristics of stability and seepage field by using the SEEP/W and SLOPE/W modules in Geo - Studio. The results show that the landslide stability is worse when the smaller permeability and the bigger water dropping speed happen; the bigger permeability coefficient is the less impact on the stability of landslide when reservoir reduces the water table; the landslide stability will increase when the permeability coefficient is very big. The study provides references for prevention of reservoir landslide.

\section{The reservoir landslide}

The stability of the reservoir bank landslide is closely related to the fluctuation of reservoir level. The water level fluctuation changed the seepage and physical and mechanical properties of rock mass, and affected the stability of landslide. Landslides had occurred, both at home and abroad, caused by the reservoirs storage and changes of water level, in 2003, the landslide of Qian Jiangping occurred when the three gorges reservoir area store to $135 \mathrm{~m}^{[1]}$, In 1963 , the Vajont reservoir landslide killed more than 2000 people in Italy ${ }^{[2]}$.

Reservoir landslide is related to internal factors such as geological structure. Its external factor is mainly water lifting effect ${ }^{[3-9]}$. The reservoir landslides frequently occur in the three gorges. One landslide was selected in the three gorges reservoir to establish geology model, and it is analyzed under the action of water dropping by using numerical simulation software Geo-studio. The study will provide some reference for prevention of reservoir landslide.

\section{Landslide geological model}

The upper landslide material is Colluvial deposit, it mainly is the quaternary accumulation $\left(\mathrm{Q}^{\mathrm{del}}\right)$ and residual diluvial layer $\left(\mathrm{Q}^{\mathrm{el}+\mathrm{dl}}\right)$, it includes clay and chipped rocks, loose structure and clutter. The underlying bedrock of the landslide is lower Jurassic xiangxi group $\left(\mathrm{J}_{1} \mathrm{x}\right)$, the attitude of bedrock is $268^{\circ}<27^{\circ}$, the bedrock fissures developed. The engineering geological profile is shown in Fig.1. 


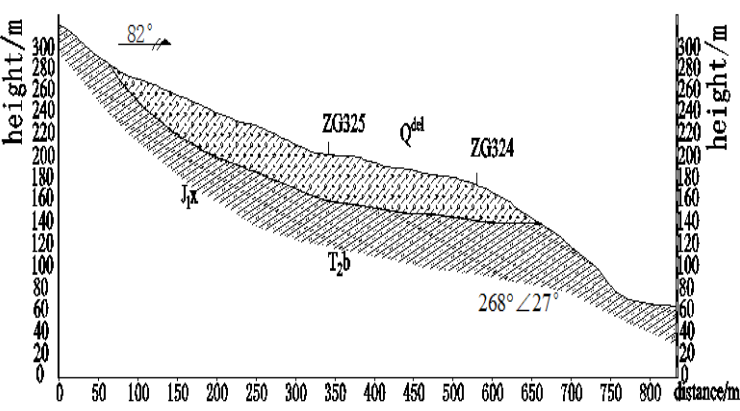

Fig. 1Engineering geological profile

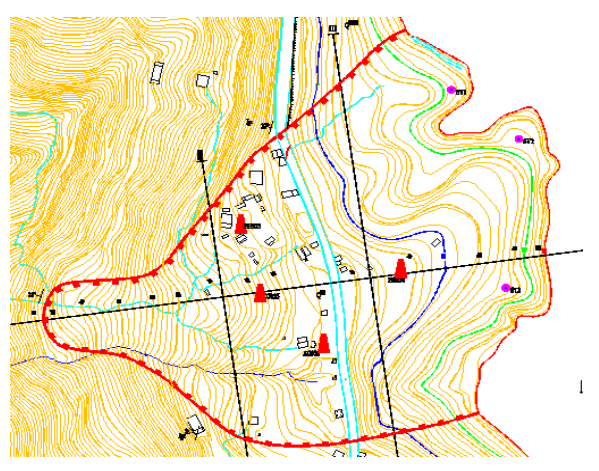

Fig. 2 Monitoring arrangement of landslide

\section{Monitoring results of landslide deformation}

GPS monitoring network layout

According to the deformation characteristics of the landslide, one vertical and one horizontal monitoring section are selected. There are four GPS monitoring points were arranged on the landslide. They are ZG323, ZG324, ZG325and ZG326. The monitoring points arrangement are shown in Fig. 2

The monitoring data analysis

Reservoir level and the cumulative displacement monitoring curves is shown in Fig.3, the cumulative displacement curve has a obvious step, all four monitoring points have changed at the same time, which means that the landslide deformation had occurred in the whole landslide. The biggest deformation is ZG326, the cumulative displacement was always greater than several other points, it shows that the landslide deformation is bigger on the right side. The three gorges reservoir level declines in April to June each year, the landslide deformation increase.

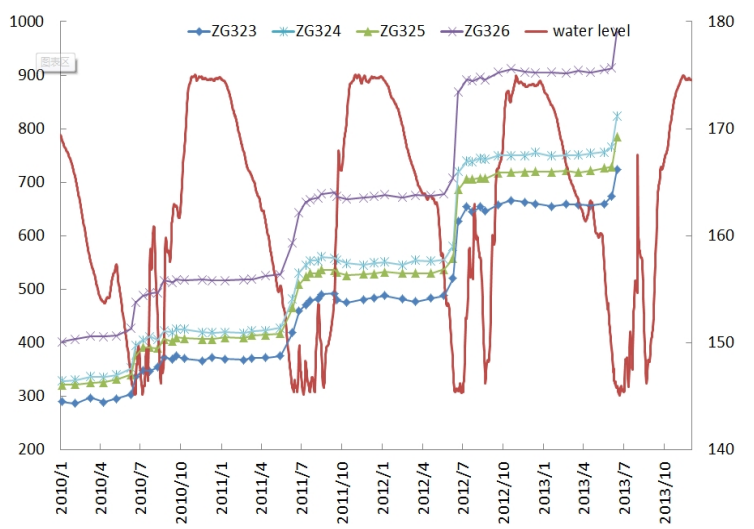

Fig. 3 Time-cumulative displacement curves of GPS monitoring

\section{Numerical simulation of landslide stability}

The basic theory of saturated-unsaturated seepage

According to the law of conservation of mass and Darcy's law, two-dimensional anisotropic saturated-unsaturated seepage control equation without considering the seepage on the $\mathrm{Z}$ axis $\operatorname{direction}^{[10]}$ :

$$
\frac{\partial}{\partial x}\left(k_{x} \frac{\partial H}{\partial x}\right)+\frac{\partial}{\partial y}\left(k_{y} \frac{\partial H}{\partial y}\right)=m_{w} \rho_{w} g \frac{\partial \theta}{\partial t}
$$


In the formula, $\mathrm{H}$ is the water head, $\theta$ is volumetric soil water content, $\mathrm{k}_{\mathrm{x}}, \mathrm{k}_{\mathrm{y}}$ for permeability coefficient on the direction of $\mathrm{x}, \mathrm{y} . \mathrm{t}$ is time, $\rho_{\mathrm{w}}$ is water density, $\mathrm{m}_{\mathrm{w}}$ is storage coefficient. Formula (1) is the general expression of a two-dimensional saturated and unsaturated seepage. It has multiple solutions under the usual condition. Only with certain definite condition, such as the geometric boundary conditions and initial conditions of seepage water head distribution, this can satisfy the conditions of a specific solution.

Boundary conditions mainly include two types of constant head boundary and constant flow boundary. When one of the reservoir scheduling scheme has been determined, if only considering reservoir water function. The landslide on $\Gamma_{1}$ head is known. The constant head boundary conditions are as follows:

$$
\left.H(x, y, t)\right|_{\Gamma_{1}}=\varphi(x, y, t)
$$

In the formula, $\Psi$ is the potential function. If the normal supply of the trailing edge of the landslide mass or slide bed boundary $\mathrm{r}$ is established. The flow boundary conditions are as follows:

$$
\left.k \frac{\partial H}{\partial n}\right|_{\Gamma_{2}}=q(x, y, t)
$$

In the calculation of saturated and unsaturated seepage, the initial state when $t=0$, the water head distribution has the key influence on subsequent seepage calculation. So the initial state of stable seepage calculation should be done before the unsteady seepage calculation, as the subsequent calculations of initial conditions. That is:

$$
\left.H(x, y, t)\right|_{t=0}=H(x, y)
$$

Calculation model and the physical and mechanical parameters

The groundwater seepage field and the slope stability are simulated by using SEEP/W and SLOPE/W module in Geo -Studio. The geological model is established from Fig.1.The finite element calculation model is shown in Fig.4.

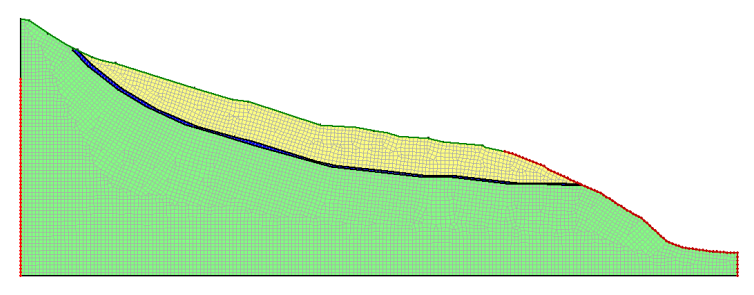

Fig. 4The calculation model

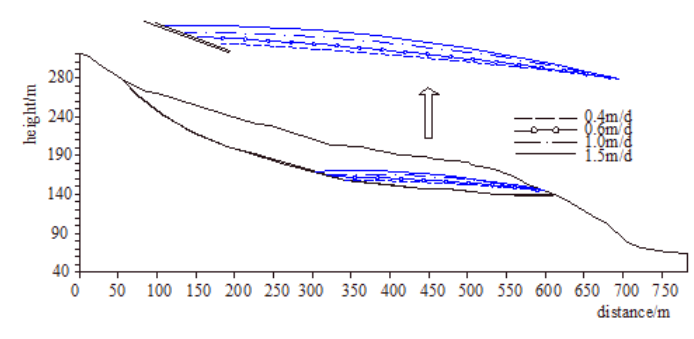

Fig.5 The underground water line

Stability calculation and results analysis

The four different kinds of reservoir water dropping rates are used to reflect the influences on the stability of the landslide, and it is determined for four working conditions according to the real change of the three gorges reservoir level. The four conditions is as followed: (1) water level decreased from $175 \mathrm{~m}$ to $145 \mathrm{~m}$ at a speed of $0.4 \mathrm{~m} / \mathrm{d}$. (2) water level decreased from $175 \mathrm{~m}$ to 145 $\mathrm{m}$ at a speed of $0.8 \mathrm{~m} / \mathrm{d}$. (3) water level decreased from $175 \mathrm{~m}$ to $145 \mathrm{~m}$ at a speed of $1.2 \mathrm{~m} / \mathrm{d}$. (4) water decreased from $175 \mathrm{~m}$ to $145 \mathrm{~m}$ at a speed of $1.5 \mathrm{~m} / \mathrm{d}$. 
The SEEP module was used to simulate the groundwater seepage field change under four working conditions, which is that water level declines respectively by $0.4 \mathrm{~m} / \mathrm{d}, 0.8 \mathrm{~m} / \mathrm{d}, 1.2 \mathrm{~m} / \mathrm{d}$ and $1.5 \mathrm{~m} / \mathrm{d}$. The underground water levels in the sliding body as shown in Fig.5. when the water levels is descend to $145 \mathrm{~m}$ in the reservoir, it is discovered that the basic law of the underground water level presents a convex, and the convex trend of underground water level is the more obvious when the decent speed of reservoir water levels is gradually increasing from $0.4 \mathrm{~m} / \mathrm{d}$ to $1.5 \mathrm{~m} / \mathrm{d}$. When the water level drops to $145 \mathrm{~m}$ the underground water level in sliding body is significantly higher than the water level. There is a hydraulic head pressure in the sliding body, and the dynamic water pressure is point to outside.

The stability changes of the landslide are simulated in the four different reservoir water level by considering the matrix suction Morgenstern - Price analysis ${ }^{[1]}$ in SLOPE module. Four conditions are also considered which the reservoir water dropped from $175 \mathrm{~m}$ to $145 \mathrm{~m}$ at the speed of $0.4 \mathrm{~m} / \mathrm{d}$, $0.8 \mathrm{~m} / \mathrm{d}, 1.2 \mathrm{~m} / \mathrm{d}, 1.5 \mathrm{~m} / \mathrm{d}$ respectively. The stability coefficient is obtained under three working conditions with the relation of water level change as shown in Fig.6. As shown in the Fig.6, the stability coefficient of landslide is gradually reducing with the falling of water level under three kinds of working conditions. While water level fall to around $158 \mathrm{~m}$ the stability coefficient will continue to fall, but the rate of descent become slow. For each kind of condition, the stability coefficient with the greater dropping rates is relatively smaller than that with less dropping rates.

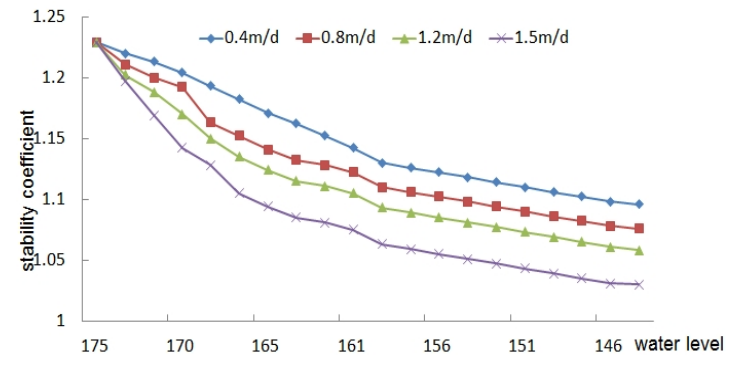

Fig. 6 The change rule of the stability

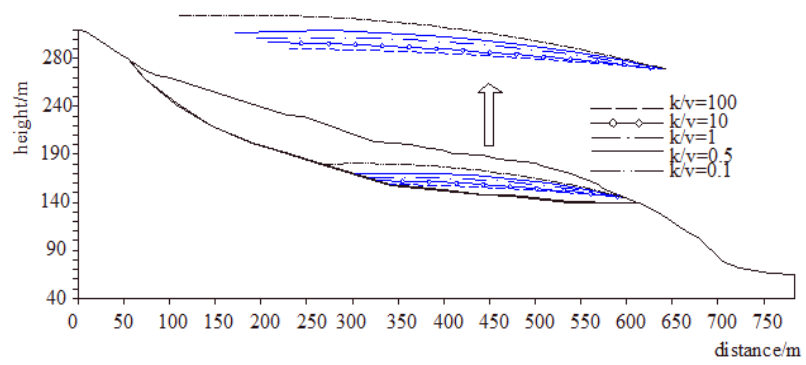

Fig. 7 The underground water level

\section{The influence of the permeability coefficient on stability}

Permeability coefficient $(\mathrm{k})$ is the main influencing factors of the stability of landslide. The dropping speed $\mathrm{v}$ is set to $1 \mathrm{~m} / \mathrm{d}$, and it is calculated as $\mathrm{k} / \mathrm{v}=0.1, \mathrm{k} / \mathrm{v}=0.5, \mathrm{k} / \mathrm{v}=1, \mathrm{k} / \mathrm{v}=10, \mathrm{k} / \mathrm{v}=$ 100 , namely $\mathrm{k}=0.1 \mathrm{~m} / \mathrm{d}\left(1.2 \times 10^{-6} \mathrm{~m} / \mathrm{s}\right), \mathrm{k}=0.5 \mathrm{~m} / \mathrm{d}\left(6.0 \times 10^{-6} \mathrm{~m} / \mathrm{s}\right), \mathrm{k}=1 \mathrm{~m} / \mathrm{d}\left(1.2 \times 10^{-5} \mathrm{~m} / \mathrm{s}\right), \mathrm{k}$ $=10 \mathrm{~m} / \mathrm{d}\left(1.2 \times 10^{-4} \mathrm{~m} / \mathrm{s}\right), \mathrm{k}=100 \mathrm{~m} / \mathrm{d}\left(1.2 \times 10^{-3} \mathrm{~m} / \mathrm{s}\right)$. Water level is set to fall from $175 \mathrm{~m}$ to 145 $\mathrm{m}$.

The change law of underground water level is shown in Fig.7, there are almost on the convex tendency, and the tendency is more obvious when the permeability coefficient decreases. The attitude difference of the underground water level inside and outside is bigger at the same time, and dynamic water pressure pointing to the outside of the sliding body, there are more harmful for the stability of landslide.

When water level decreased from $175 \mathrm{~m}$ to $145 \mathrm{~m}$, the changes of the stability coefficient of landslide is shown in Fig.8. It is shown from the Fig.8, when k/v is equal to 0.1 or 0.5 or 1 , and the water level drop down, the stability coefficients of landslide reduced. When the permeability coefficient of landslide reduce from $1.2 \times 10^{-5} \mathrm{~m} / \mathrm{s}$ to $1.2 \times 10^{-6} \mathrm{~m} / \mathrm{s}$, the stability coefficient decreases, it is shown that the stability decreased when smaller permeability coefficient is smaller and the faster dropping of reservoir level. When $\mathrm{k} / \mathrm{v}$ is equal to 10 and 100 , it is the permeability coefficient of landslide is bigger, the stability coefficient increase, therefore it's good for the stability of landslide, because the groundwater of landslide body can faster outflow the landslide 
body.

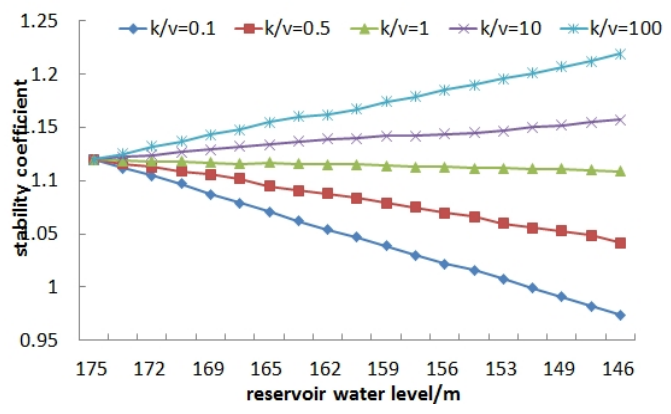

Fig. 8 The change rule of the stability under different k/v

\section{conclusion}

Stability of landslide is closely related to the water level dropping speed and coefficient of permeability. When the permeability coefficient of landslide is smaller, and the bigger water dropping speed, the stability of landslide is worse. When the permeability coefficient of landslide is bigger, the water dropping speed has no influence on the stability of landslide decreasing, and even it makes the stability coefficient to increase.

\section{Acknowledgements}

This study was supported by the scientific research project of Hubei Province (2012FFA040).

\section{References}

[1] Shirong Xiao,Fuxin Jiang: Journal of rock mechanics and engineering.vol25(5):1023-1030(In Chinese)

[2] Zhongcun Hazozhi:The theory of reservoir landslide;journal of maintain water and soil.1990.2(10) : 53-64.

[3] Wu Yi,Shaoping Meng,Qinglin Yi:geological,Geological publishing,Beijing,2007(In Chinese)

[4] Lumb, P, B: Proc.Of sym.On Hong Kong Soils. 1962.

[5]Ng,C.W.Shi: Computers and Geotechnics, 1998,22(1):1-28.

[6]Yunpeng Liu,Yunqiu Huang:journal of engineering geology,2011,19 ( 3 ) : 417-427.(In Chinese)

[7]Dapeng Zhu:The research of three gorges reservoir area typical accumulation landslide mechanism and deformation prediction.Wu Han,China geological university.2010(in Chinese)

[8]Weigong Chen,Keqiang He,Linna Sun:Journal of disaster.2013.7 : 6-10(In Chinese)

[9]Shirong Xiao,Zhiyu Hu, Shusheng Lu:Proceedings of the national academy of sciences.2013,30 ( 11 ) : 39-44.(In Chinese)

[10]Xiaohong Liu:The study on the regular of the reservoir landslide water dynamic increment displacement response and its stability.Qingdao university of technology,2013(In Chinese) 
International Forum on Energy, Environment Science and Materials (IFEESM 2015)

[11]Zhiyi Li,Zhiji Wang,Yuyun Yang:The basis of engineering geology. China geological university publishing, Wu Han, 1989(In Chinese) 